\title{
Organized Hypocrisy in EFL Teacher Training Programs
}

\author{
Abdul Karim \\ Graduate Research Student, School of Educational Studies, Universiti Sains Malaysia, \\ khasan13aiub@gmail.com
}

\author{
Abdul Rashid Mohamed \\ Prof., School of Educational Studies,Universiti Sains Malaysia, richsesusm@gmail.com \\ Shaik Abdul Malik Mohamed Ismail \\ Assoc. Prof., School of Educational Studies,Universiti Sains Malaysia, \\ samohame@gmail.com
}

\section{Mohammad Mosiur Rahman}

Graduate Research Student, School of Languages, Literacies and Translation, Universiti

Sains Malaysia, mosiurbhai@gmail.com

Embracing the reasons for the failure of donor-sponsored English-teacher training programs is very critical since it precedes the revisions, improvements and quality assurance for the futuristic training programs. Ideating such philosophy, the current study concerns the blatant penetration with regard to the donor-aided training programs in Bangladesh. Conceptualizing the Organized Hypocrisy $(\mathrm{OH})$ theory, the current study, particularly, explored to seek the answer as to how $\mathrm{OH}$ is trivializing the donor-funded English teacher training programs in Bangladesh. A systematic review process has been adopted concerning the donor-aided English teacher training programs, mobile learning theories and teacher development theories. The review yielded critical insights to apprehend the phenomena affecting the donor-sponsored training programs in the respective context. The study revealed that outright violation of donor's mandates and policies, and mainstreaming gaps resulted in the failure of the donor-sponsored training programs. Disputing the commitments from donor's part is identified ubiquitous in the training programs.

Keywords: EEL, Teacher training, Organized Hypocrisy, Mobile learning, Teacher development

\section{INTRODUCTION}

Concerning the inevitable role of this in thriving the teachers' skills, and thereby, securing students' learning (Karim, Mohamed \& Rahman, 2017), teacher training is

Citation: Karim, A., Mohamed, A. R., Ismail, S. A. M. M., \& Rahman, M. M. (2018). Organized Hypocrisy in EFL Teacher Training Programs. International Journal of Instruction, 11(2), 437-450. https://doi.org/10.12973/iji.2018.11230a 
mandated central to the national education policies in most countries (Shohel \& Banks, 2012). Training has been perceived instrumental to the enrichment of teachers' teaching skills. Moreover, the essence of yielding skilled teachers is training. However, teacher trainings, although designed incorporating the effective components, in a large scale, fail to bring distinguishing changes in teachers' classroom practice. Pointing, particularly, to the English teachers and their training programs, even the economically privileged countries, like Japan, China and Korea, are yet to attain broader success in training them (Hamid, 2010). Comparing to such regions in East Asia, the status of teacher training in a relatively poor economy like Bangladesh can be realized blatantly, he elaborates. Researches carried out to identify the gaps associated with the training programs in Bangladesh (e.g., Hamid, 2010, Ali \& Walker, 2014, Chowdhury \& Kabir, 2014) claim that such programs are deemed to be ineffective. The subsequent studies on the effectiveness of later English teacher training program also illustrate the potential failure of the training programs in spelling substantial changes in English teachers' classroom practice (Walsh et al., 2013; Rahman \& Akter, 2015; Anwaruddin, 2016). Inadequate resources related to English language teaching, paucity of the competent instructors, insufficient vacancy for the enrolees, and absence of updated knowledge and contemporary information etc. have been identified as the drastic problems involved with the teacher training programs initiated by the government of Bangladesh (The Daily Star, 2007; Mullick and Sheesh, 2008; Hamid, 2010). Apart from the governmental agencies such as Primary Training Institutes (PTIs) and Teacher Training Colleges (TTCs), donor-aided projects have been in operation in Bangladesh, some of which even commit to perform for a decade. The donor-sponsored projects have been associated with the aims and objectives that make teachers robust in the communicative classrooms. However, Hamid (2010) and Anwaruddin (2016) revealed that such donorfunded training programs fail to equip teachers with their committed components. Among the donors functioning in Bangladesh is Department for International Development (DfID) that financed government of Bangladesh to launch the English Language Teaching Improvement Project (ELTIP) project in 2000 (Hamid \& Baldauf, 2008). DfID also funds English in Action (EIA) set out to train English language teachers in both Primary and Secondary Schools.

Probing the training programs intrigues the elicitation that integrates the reasons for the failure, as aforementioned, of the donor funded training programs. For instance, due to lack of expertise and vision (Hamid, 2010), such programs fail to deliver expected outcomes. Conceptualizing the Organized Hypocrisy (hereafter $\mathrm{OH}$ ) suggested by Lipson and Weaver (2008), the current study accounts the subtle analysis of the donoraided English-teacher training programs in Bangladesh. The fundamental aim set by the study is to uncover how $\mathrm{OH}$ has been trivializing the donor-funded English teacher training programs in Bangladesh.

\section{METHOD}

Concerning the aim of the study, the current study adopted a systematic review process, and reviewed the extensive literature related to the donor-funded English teacher training programs in Bangladesh, mobile learning theories and teacher development 
theories. Boslaugh (2007) defines secondary data analysis as "In the broadest sense, analysis of data collected by someone else" (p. 9). Secondary data analysis has been identified populace, and thus, was adopted by many researchers in their studies pertinent to teacher training programs and other area of applied linguistics. (see Ellis \& Sagarra, 2010; DeKeyser, 2013; Karim \& Rahman, 2016; Rahman, Pandian, Karim \& Shahed, 2017; Karim, Mohamed \& Rahman, 2017).

The conduct of a systematic review depends heavily on the scope and quality of the included studies. Thus, systematic reviewers may need to modify their original review protocol during its conduct (Moher, Liberati, Tetzlaff, Altman, \& Prisma Group, 2009). In order to search peer-reviewed articles, a systematic search was conducted in SCOPUS, Web of Science and Google Scholar for the last couple of years (1992present), with relevant keywords, such as English teacher education program, English teacher training programs in Bangladesh, Teacher development theories, and Mobile learning theories. Some of the articles had to be excluded due to their irrelevance. In the search of SCOPUS and web of science, a considerable number of articles was collected to be specific to our topic. In the Google Scholar search, 15 articles were found to fit to our topic. In analysis, the paper firstly, presents teh $\mathrm{OH}$ and secondly, elaborates on how $\mathrm{OH}$ prevails in English teacher training programs. The discussion is put in a thematic manner based on the related variables of the study and will be allowed to discuss the phenomenon in a structural way.

\section{Data Presentation}

The present qualitative study concerns answering the following question: How has organized hypocrisy been trivializing the donor-sponsored training programs in Bangladesh?

In order to reveal the answer, we have sectionalized our discussion into three parts. Firstly, we have drawn a vignette conceptualizing OH. Secondly, being linear to the components of $\mathrm{OH}$, a critical analysis has been presented on the teacher training projects, and thereby, we have revealed the $\mathrm{OH}$ of these projects by comparing and contrasting the theory of $\mathrm{OH}$ and the reality of the teacher training programs. Finally, we have concluded with implications of the major findings of the study.

\section{Organized Hypocrisy}

Lipson and Weaver (2008) define $\mathrm{OH}$ as the contradictions or discrepancies prevailed between talk, decisions and actions, yielded from "inconsistent material and normativeideational pressures on organizations" (p. 4). When it comes to international institutions, as they explicate, $\mathrm{OH}$ subsumes the disparity between what an institution as a collective actor commits and what it fulfils in reality. It means that institution espouses certain goals, ideals and policies; however, it is highly likely that it fails to imply the ideologies and policies, and thus, fails to achieve the goals for what it is functioning. $\mathrm{OH}$ can also be generated from the paradox existing between what institution is supposed to commit and do in the idealistic world, and what it is able to accomplish in reality, given the political, financial and cultural environments thwart the committed functions of the institution (Lipson \& Weaver, 2008). OH in international institutions has three different 
forms, as they identify. The most conspicuous form of $\mathrm{OH}$ is the instantaneous violation of the mandates and policies set by the institution. Lipson and Weaver (2008) suggest that the evidence of such kind of "organized hypocrisy can be found in its violation of its own environmental and social policies in its own infrastructure projects" (p. 5), meaning that such hypocrisies can be visible in the policies developed of the organization. The second category of $\mathrm{OH}$ is emerged in the form of mainstreaming gaps. This happens when the organization commits to bring sustainable development, but it does not comply allow human and financial resources to comply with this sustainable development (Lipson \& Weaver, 2008). The third form of $\mathrm{OH}$ is, as they identify, "the product of states within international regimes.... [the] states formally express commitment to a regime's principles and norms, while violating them in practice" (p. 6). Shown below is the categorization of $\mathrm{OH} ; \mathrm{OH}$ may arise from any of these in an institution.

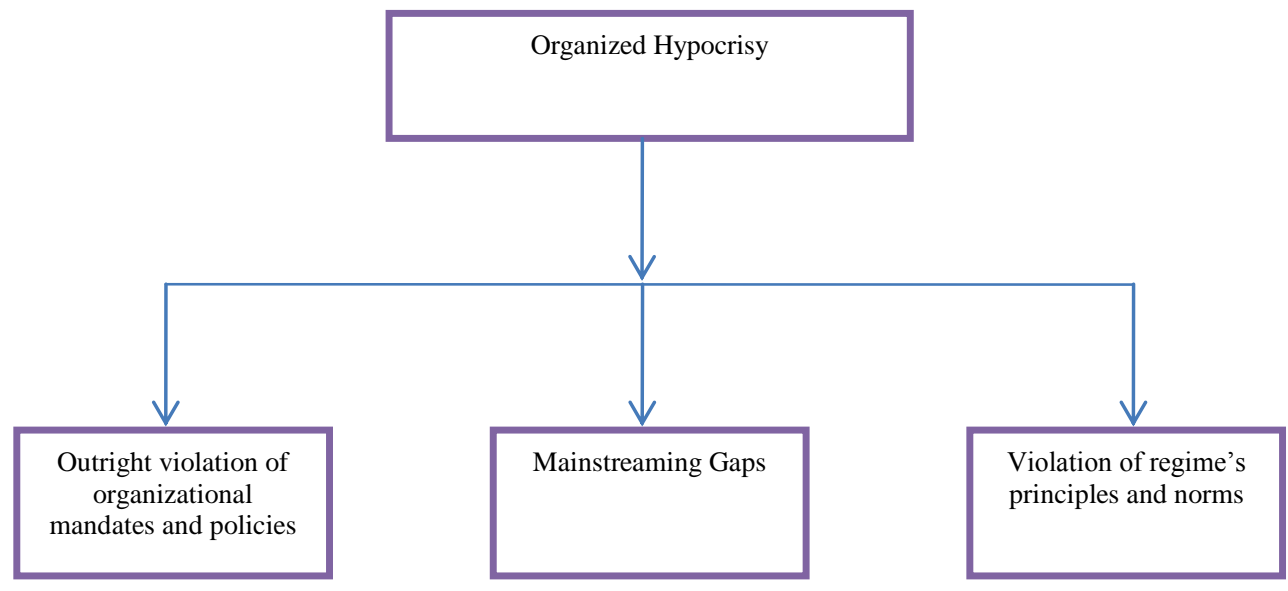

Diagram 1

Classifications of $\mathrm{OH}$ (Lipson \& Weaver, 2008)

\section{FINDINGS}

\section{Outright Violation of Donor's Mandates and Policies}

The current section concerns the illustration of 'outright violation of Donor's mandates and policies' with substantial evidences documented in multiple scholars' elicitations. For elaboration, the authors provide a precise overview of the respective training programs regarding their aim and objectives coupled with the explanation of their outright violation of mandates and policies with a view to substantiate the gateway they exploit to commit $\mathrm{OH}$.

The first English teacher training program funded by DfID was ELTIP, which arranged a 13-day training session for the English teachers having the objective ahead, introducing teachers with Communicative Language Teaching (CLT) (Hamid, 2010). However, DfID left the project after the first phase of its functioning (ELTIP- I) and 
devised new program-EIA, he reports. It is surprising that one of the objectives of EIA also was to introduce English teachers with CLT through training (Chowdhury \& Kabir, 2014). The scintillating question, therefore, is whether the project-ELTIP-launched hitherto failed to introduce teachers with CLT. And was it the reason why the later project accounted the same objective? Investigating the impact of the English-teacher training programs, Shrestha (2012) reports that teachers fail to adopt CLT in their classroom practice, which is commensurate with the findings elicited by TQI-SEP (2007), elaborating the similar fact that teachers prone to follow the conventional method-Grammar Translation Method (GTM)-in the classroom. Such remarks imply that ELTIP failed to equip teachers with CLT method. It is also, however, noteworthy that DfID stopped funding the project in 2002, and left 55000 teachers untrained. DfID's policies here seem vulnerable since they started the first project and left it suddenly, and launched another project with similar objectives ahead. Nevertheless, DfID set out to improve the English language teaching in Bangladesh. Leaving ELTIP resembled controversy in its mandates. It violated own policies in this regard. One may argue that DfID left ELTIP and devised another project- IA; therefore, nothing was wrong with it. Such action of DfID resulted in inconsistency in teachers' training, which a seemingly poor nation (Hamid, 2010) like Bangladesh could hardly compensate. ELTIP was stopped leveraging fund in 2002 and EIA was devised in 2008. If we retrospect, it would be easier for us to realize the aftermath of DfID's leaving, provided the interim of six years (see Hamid, 2010).

Another contention drawn is, EIA training program incorporated equipping primary and secondary education with English, which was substantially the same mission ELTIP envisaged (Hamid, 2010). However, one iniquity observed in EIA regarding the fact that it provided teachers with mobile phones preloaded with audio-visual resources related to classroom practice. One may argue that EIA largely focused on contributing to the national economy by producing citizens equipped with the communicative ability in English language. In sum, by introducing teachers with CLT and disseminating the resources through mobile phones, EIA envisioned to enrich the communicative competence of, according to English in Action website, 25 million people.

Now let us have a closer look to ELTIP's objective. As mentioned earlier, ELTIP also entailed introducing teachers with CLT. Thus, the question is, where had actually the difference lied between the earlier introduction and the later one. To reveal the answer with more clarity, let us elaborate on CLT. According to Larsen-Freeman and Anderson (2011), concerning the focus of CLT, it has been identified that meaningful activities in both oral and written form to thrive communicative competence are emphasized. Therefore teachers' introduction with CLT potentially refers to their introduction with the communicative activities, which corresponds the objective of both ELTIP and EIA. As such, EIA's objective was not fundamentally different from that of ELTIP. Moreover, seemingly evident is that teachers were the sole focus in EIA training program as they were in ELTIP. Therefore, how EIA differs in this regard from ELTIP is the crucial issue to ponder. Why DfID, then, stopped funding ELTIP and launched a new project. Hunter's (2009) elaboration leads us to an ambiguous answer that the rationale for a new project is probably known to the Bangladeshi policymakers and 
DfID. I, however, can conclude it stating that regarding ELTIP, DfID violated its own mandates and concerning EIA, it just paraphrased its mandates.

Another emphasis drawn by EIA is producing economically conducive citizens. Then, the pertinent question is, did it train English language teachers or English language learners? To reveal the answer, let us have another critical look to the aim section of EIA. EIA aimed at improving the English language proficiency of 25 million people in Bangladesh (Islam, 2015). To attain so, the project had developed materials and designed teacher professional development activities for English teachers in both primary and secondary schools (Shrestha, 2012). It was expected that these teachers would support millions of school children in developing their competence in English language, she comprehends. So, seemingly EIA solely trained English teachers. Anwaruddin (2016) also delineates that EIA incorporated teachers' knowledge of content and instructional processes. On top of that, EIA website containing the information of EIA illustrated that it only concerned teachers and teaching materials to be practiced in the classroom (English in Action). Such illustration does not necessarily make us embrace the difference between ELTIP and EIA. Because, teacher trained from ELTIP could also be beneficial for producing economically contributive citizens in the same way EIA trained teachers are expected to produce. Therefore, 'equipping 25 million people' is written, perhaps, only to tantalize the stakeholders for securing EIA's access to Bangladesh. In addition, mentioning this, DfID reshaped its mandates, which this study, in what follows, examines how EIA is attaining them.

In EIA, no sectionalisation is evident regarding the teachers participating in the training programs, yielding a major issue that participating teachers in ELTIP and EIA are mutually inclusive. EIA does not gather data regarding the distinction between teachers trained from ELTIP and teachers do not get trained from ELTIP. Before launching the project, the funder-DfID-should have clearly articulated that participant teachers in ELTIP had no opportunity to take part in EIA. However, it is apparent that the pattern of training the English teachers in EIA differ from that of ELTIP, provided the incorporation of technology in EIA. Admitting this distinction in terms of training pattern, however, cannot justify EIA's skip of the categorization of the English teachers. EIA should have been selective in this regard. Therefore, the pertinent question is, how many teachers have got training from EIA. Another question is, how many teachers EIA and ELTIP had provided training to. The answer elicited by Hamid (2010) illustrates that ELTIP being funded by DfID in their first phase trained 5000 secondary-school English teachers; however, ELTIP was committed to train 60,000 English teachers. Regarding the number in EIA, the story becomes cynical. According to Perez-Gore and Burton (2014), EIA had targeted to train 76,500 English teachers within nine year (2008-2017). However, by April 2014 it had managed to train 12,500 teachers (English in Action), and it was expected to reach 51000 teachers by the end of 2017. I reckon the answer becomes clear. For elaboration, EIA started its function in 2008. After more than half of its tenure, it trained 12,500 teachers. One need not be with superfluous intelligence to embrace that EIA would not be able to reach even the half of the number $(25,000)$ of teachers, as per its final commitment of 51,000 . Therefore, in sum, the total 
number of teachers trained by DfID-funded ELTIP and EIA would be probably 30,000 $(5,000+25,000)$, while ELTIP solely committed to 60,000 and EIA to 75,000.

In fact, DfID funded EILTIP and EIA violated their commitment to a larger scale. DfID, without reaching the target people, stopped funding ELTIP, and launched EIA, which is also potentially unable to reach the target people. To embrace it more clearly, let me elaborate on another commitment to portray how EIA's synchronized hypocrisy takes place. Aiming at 25 million, EIA reached only one million students by 2014. By 2017, it expected to reach 7 million students, which, like the teachers' case mentioned earlier, was practically impossible. Apart from ELTIP and EIA, addressing the classroom realities and student needs, Teaching Quality Improvement in Secondary Education Project (TQI-SEP, 2005-2011), jointly funded by Canadian International Development Agency and the Government of Bangladesh, aimed to provide 28,000 English teachers with pre- and in-service training (Hamid, 2010). It is cynical that only one-fifth of the English teachers received this training. Such phenomenon, we firmly advocate as ELTIP, TQI-SEP and EIA's violation of their mandates, given Lipson and Weaver (2008) reports the evidence of such $\mathrm{OH}$ is found in institution's own documentations. We, to a large extent, therefore, depended on EIA website and scholarly articles to collect data for the current study.

Concerning the technology, Shohel and Bank's (2010) study demonstrates the incorporation of iPod as the media player, which was provided for the trainee teachers in EIA. However, study carried out by Power and Shrestha (2010) suggests that it is not iPod, rather simple mobile phones distributed to the participating teachers. Later, Shrestha's (2012) elaboration also endorses the use of mobile phone, which was identified as 'trainer in your pocket' by Walsh et al. (2013). The replacement of iPod with mobile phone suggests how EIA had disjoined its commitment in terms of technological support. Mobile phones serve multidimensional purposes while iPod only includes listening to and watching the audio and visual resources. Because of the multipurpose associated with mobile phone, it was bound to deviate teachers from learning.

English for Teaching, Teaching for English (ETTE) was another project funded by British council that functioned from 2008-2010, the same time when EIA had launched. DfID should have been cognizant about ETTE. It is also worth mentioning that funds for EIA and ETTE were leveraged from the same country, the UK. The relevant question, as Hamid (2010) raises, is why the "two projects originating in the same organization in the same country (UK) were operating with similar goals almost simultaneously" (p. 301). The scattered operation of different training programs from same origin was really frustrating for the teachers. For instance, with similar goals ahead, different training programs imposes different materials and staffs on the teachers, resulting in teachers' bewilderment. Teachers fail to settle down on a meticulous strategy.

\section{Mainstreaming Gaps}

This section of the study amalgamates the $\mathrm{OH}$ resulted from 'mainstreaming gaps'. To achieve the critical understanding, this section aggregates findings of the previous 
studies in relation to the pertinent theories drawn by these studies. It is adopted to delineate the $\mathrm{OH}$ with substantial evidences.

Building on the teacher development approaches integrated by Hargreaves and Fullan (1992), Anwaruddin (2016) claims that EIA lacked egalitarian approach when it came to the emphasis on three approaches-knowledge and skill development, self-understanding and ecological change-to teacher development. EIA seemed to focus relatively more on knowledge and skill development and self-understanding than ecological change. EIA adopted school-based professional development for the teachers and prioritized low-cost mobile phones containing the materials related to classroom practice (Anwaruddin, 2016). Two layers of organized hypocrisy could be observed here, in which the first one pertained to the technology and the second one concerned the resources. In the beginning of the project, it was iPod which served the purposes, the same as mobile phone does now. However, after a while EIA replaced iPod with low-cost mobile phones to diffuse resources for the teachers. To elaborate, its incorporation of mobile technology was a fallacy, given the UNESCO (2008) report entailing that $30 \%$ of the population in Bangladesh was yet to obtain the electricity connection, which later Mahruf et al. (2012) corroborate. Walsh et al. (2013) also identify teachers experiencing the problem due to insufficient electricity connection. Teachers reported that they could not charge mobile phones and speakers because of the resistance in electricity supply. Therefore, how EIA could initiate such a scheme without considering the realistic constraints is still a pertinent question. EIA's orientation of technology did not comply with the context. Therefore, I can dub as the second form of $\mathrm{OH}$, which concerns the organization's commitment to bring sustainable development; however, it did not allow human, financial and other resources (e.g., material, electricity) to comply with this sustainable development. EIA knew the hindrances in electricity supply, but still developed training and teaching materials incorporating technology which demanded electricity to run.

Besides, Anwaruddin (2016) explicates that, these resources facilitate teachers' knowledge and skill development squeezes the components necessitated for fostering teachers' professional learning and growth. In respect to self-understanding, his study uncovers that teachers' beliefs about English, language learning and teaching are dubious, even after attending the training program in ELTIP or EIA (see Karim, Mohamed \& Rahman, 2017 for more details). Karim, Mohamed, Rahman and Haque (2017) also reveal that teachers perceive the method to be adopted in the classroom as confounding. In addition, Anwaruddin (2016) claims that EIA eluded the consideration of context, where teachers live, learn and teach. And only for such elusion, it incorporated technology for teaching and learning. Apart from these is the discussion, as elicited by Karim, Mohamed and Rahman (2017), integrating the mobile learning theory to measure the mobile-oriented learning of EIA, it suggests that there was a massive distinction prevailing between them. For instance, as they illustrate, micro teaching, a core part of mobile learning which subsumes planning, teaching, observation, replanning, re-teaching and re-observation, was absent in EIA. Moreover, they endorse Anwarudding's (2016) claim mentioning that preloaded in the mobile phones, 12 modules subjecting to CLT debilitates teachers' potentiality to design lesson plans for 
their own classroom practice. Instead, to bring self-sufficiency, EIA could have developed the training program including, apart from 12 CLT modules, the preparation for planning lessons addressing the situational needs of the learners.

Considering the support for teachers From ETTE, we observe that with a view to enhance teachers' classroom performance, it facilitated primary teachers' accessibility to materials, methods and opportunities for their professional training and development. Now the question is, who would do what with such accessibility. Our teachers are struggling to complete their textbook in a given year, therefore, managing time to access such staffs on their part is an impossible affair. Surely, they do not have the repertoire to go through these materials and method, given that primary school teachers are not subject specialists and they are secondary school graduates (Hamid, 2010). Without the proper assistance, they could not initiate learning by self. We are pointing out these issues because ETTE had functioned for two years. How could ETTE manage to reach the primary school teachers within a short period of time? The answer of this question, we want to elicit by presenting the number of teachers ETTE managed to reach, which was only 2,000. Now, what happens when training programs get finished providing some with training, and leaving a large scale untrained is interesting. The diversity in teachers' classroom practice occurs. The trained ones try to incorporate what they learned in the training while the untrained ones follow the conventional approaches. Since majority remain untrained, they become the dominating force and discourage the integration of versatile activities in classrooms. Ultimately, the classroom becomes textbook- and teacher-centred. DfID's ELTIP and EIA, British Council's ETTE and their jointly funded TQI-SEP spelled such problem for our teachers.

Concerning TQI-SEP, the underlying reason for the failure to reach the large section of the teachers was the lack of full-time instructors, provided they happened to be the hired ones who lacked motivation and commitment because of their casual basis employment (Hamid, 2010). The trainers had been provided with 6-day training before they started providing training to the trainee teachers. Now the question is, why temporary trainers were recruited with such a handful amount of training. How pragmatic was it to perceive that 6-day training program as effective for yielding professionalism in them to satisfy the needs of 28,000 teachers--knowing that our teachers had been struggling to impart English language competence among the students? We would like to define it as a kind of eyewash since such training program acted as a sailor with no destination. Furthermore, the training program for teachers was only for 21 days. How could TQISEP expect to equip teachers within this short period, given the fact that Teacher Training Colleges (TTCs) and Primary Training Institutes (PTIs) fail to equip teachers even through one-year certificate programs (Malek et al., 2009)? Islam (2003) and Hamid (2010) reverberate concerning the contents harnessed in TTCs and PTIs, reporting that they follow general curricula in which $6.3 \%$ of the curriculum is related to English teaching in PTIs and 5\% of the curriculum is related to English language.

\section{CONCLUSION AND IMPLICATION}

The strength of the current study lies in the interpretation of the downsides of the donorfunded English-teacher training programs from organizational point of view, a relatively 
new incorporation in the paradigm of education. Subsequently, we would like to draw our conclusion by first admitting our modest intent of shedding light on the OH. It is, nevertheless, noteworthy that " $\mathrm{OH}$ can arise unintentionally, or be unavoidable, and is therefore not always hypocrisy in the sense of conspicuously chosen duplicity" (Lipson $\&$ Weaver, 2008, p. 4-5). The findings of the study conspicuously suggest that 'outright violation of donor's mandates and policies' and 'main streaming gaps' potentially trivialize the donor-funded training programs in Bangladesh.

Now, let us elaborate on effectiveness of the findings yielded by the current study. Considering the hypocrisy revealed in this study, the government can initiate stipulatory monitor to the commitments of the forthcoming English teacher training programs. It can prevent the $\mathrm{OH}$ to a considerable extent. It has been meticulously evident that critical inquiries into the program impact had not been carried out by the local researchers (Hamid, 2010). Therefore, he argues for conducting investigation into the program impact by the local authority. Only proper monitoring can shackle the dispute and inconvenience released by the donor-aided programs.

In this study, additionally, we have raised certain questions triggering the donors and their programs. These questions serve as the scaffolds for the issues to be blatantly monitored in the next programs. The local authority must open the gateway for the donors once they clearly confirm them regarding their aims and objectives set considering the context. If they commit to train only 5,000 teachers within a certain time frame, they must accomplish it. Time and again, it has been observed that when they left more than half of their targeted teachers untrained, it dismantled our education erratically, which became a big curse for a developing country like Bangladesh. The intention of the training programs must also aim at producing self-sufficient teachers. They must design their materials in a way that would spell equipped teachers, capable of developing own lesson plans, classroom materials and so on. Moreover, to bring sustainable development, they must facilitate teachers to retain what they have learned in the training program.

Furthermore, Anwaruddin (2015) explicates that the incorporation of technology cannot solely spell the students' successful language and literacy development. The teachers, as he accords, have a great role to direct the context in which technology can function and facilitate learning. Anwaruddin, therefore, claims the necessity of embracing the critical relationships among content, pedagogy and technology, and we, in this study, embark the inclusion of this in the teacher training program, because of the emphasis put by the educational researchers on the importance of adapting technology considering the context. Anwaruddin (2015), as such, pertinently elucidates that "teachers need to be equipped with necessary knowledge and skills to make appropriate uses of available Information and Communication Technologies" (p. 7). In their study, Karim, Mohamed and Rahman (2017), after exploring numerous definitions and features of mobileoriented learning which EIA integrates, categorize two aspects of mobile learning: (a) teacher training about mobile learning and technology integration, and (b) teacher training with mobile learning. In Bangladesh, EIA operates the second one; however, the necessity of the first one is more vibrant since it involves "hands on exploration of 
mobile technologies, developing mobile lesson plans, micro teaching mobile lessons, enacting mobile lessons in the classroom, reflecting on mobile lessons, planning mobilized curriculum and integrating mobile + pedagogy $=$ mobagogy which is termed by Schuck et al. (2013)" (p. 53). Therefore, needless is it to say how intensively mobile learning should be deployed in order to attain its effectiveness.

\section{REFERENCES}

Ali, M., \& Walker, A. L. (2014). 'Bogged down' ELT in Bangladesh: Problems and policy: Investigating some problems that encumber ELT in an EFL context. English Today, 30(2), 33-38.

Anderson, M., \& Larsen-Freeman, D. (2011). Techniques and Principles in Language Teaching.

Anwaruddin, S. M. (2015). ICTs in language and literacy education in Bangladesh: A critical review. Current Issues in Education, 18 (1).

Anwaruddin, S. M. (2016). ICT and Language Teacher Development in the Global South: A New Materialist Discourse Analysis. Educational Studies, 52(3), 260-278.

Boslaugh, S. (2007). Secondary data sources for public health: A practical guide. Cambridge University Press.

Ellis, N. C., \& Sagarra, N. (2010). The bounds of adult language acquisition. Studies in Second Language Acquisition, 32(4), 553-580.

English in Action (EIA). (2017). Retrieve November 4, 2017, from https://www.eiabd.com/eia-component/secondary-education.html

Hamid, M. O., \& Baldauf, R. B. (2008). Will CLT bail out the bogged down ELT in Bangladesh?. English Today, 24(3), 16-24.

Hamid, M.O. (2010). Globalisation, English for everyone and English teacher capacity: Language policy discourses and realities in Bangladesh. Current Issues in Language Planning, 11(4), 289-310.

Hargreaves, A., \& Fullan, M. G. (1992). Understanding teacher development. Teachers College Press, 1234 Amsterdam Avenue, New York, NY 10027.

Hunter, T., \& Alderson, J. (2009). Micropolitical issues in ELT project implementation. The politics of language education: Individuals and institutions, 64-84.

Islam, Z. (2003). Bridging the gap: Curricular innovation and teacher preparation perspective in Bangladesh. Unpublished Master's thesis. Essex: University of Essex.

Islam, S. A. (2015). Language policy and practice in secondary school contexts in Bangladesh: Challenges to the implementation of language-in-education policy (Doctoral dissertation, Aalborg University). 
Karim, A., \& Rahman, M. M. (2016). Revisiting the Content-Based Instruction in Language Teaching in relation with CLIL: Implementation and Outcome. International Journal of Applied Linguistics and English Literature, 5(7), 254-264.

Karim, A., Mohamed, A. R., \& Rahman, M. M. (2017). EIA-A Teacher Education Project in Bangladesh: An Analysis from Diversified Perspectives. International Journal of Instruction, 10(4), 51-66.

Karim, A., Mohamed, A. R., \& Rahman, M. M. (2017). Delving the In-service Teachers' Beliefs about English, Language Learning and Teaching in EFL Context. International Journal of Academic Research in Progressive Education and Development, 6(2), 46-66.

Karim, A., Mohamed, A. R., Rahman, M. M., \& Haque, M. H. (2017). Teachers' dilemma bog down CLT in EFL contexts: A discussion on EFL teachers' beliefs and sources. IOSR Journal of Humanities and Social Science (IOSR-JHSS), 22(4), 112-120.

Lipson, M., \& Weaver, C. (2008, March). Varieties of Organized Hypocrisy. In ISA's 49th ANNUAL CONVENTION, BRIDGING MULTIPLE DIVIDES, San Francisco. Available at: http://www. allacademic. com/meta/p252179_index. html.

Malek, A., Begum, M., Islam, F., \& Ryad, S.S. (2009). Education science and education in Bangladesh [in Bangla] (2nd ed.). Dhaka: University Grants Commission.

Mullick, J. I., \& Sheesh, S. (2008). Teachers quality and teacher education at primary education sub-sector in Bangladesh. BRAC University Journal, 5(1), 77-84.

Power, T., \& Shrestha, P. (2010). Mobile technologies for (English) language learning: An exploration in the context of Bangladesh. Retrieved September 28, 2017, from https://scholar.google.com/scholar?hl=en\&as_sdt=0\%2C5\&q=Mobile+technologies+for $+\% 28$ English $\% 29+$ language+learning $\% 3 \mathrm{~A}+\mathrm{An}+$ exploration+in+the+context+of $+\mathrm{Bangl}$ adesh\&btnG $=$

Perez-Gore, I., \& Burton, S. (2014). English in Action (EIA) programme, Bangladesh: What's this about using mobile phones in the classroom?. Retrieved September, 28, 2017,fromhttp://oro.open.ac.uk/40760/1/_UserData_Documents_sb27846_Documents _personal_FINAL_EIA\%20workshop\%20ppt_IPGSB24082014.pdf

Schuck, S., Aubusson, P., Kearney, M., \& Burden, K. (2013). Mobilising teacher education: A study of a professional learning community. Teacher Development, 17(1), $1-18$.

Shohel, M. M. C., \& Banks, F. (2010). Teachers' professional development through the English in Action secondary teaching and learning programme in Bangladesh: Experience from the UCEP schools. Procedia-Social and Behavioral Sciences, 2(2), 5483-5494.

Shrestha, P. (2012). Teacher professional development using mobile technologies in a large-scale project: Lessons learned from Bangladesh. International Journal of Computer-Assisted Language Learning and Teaching, 2(4), 34-49. 
Teaching Quality Improvement in Secondary Education Project (TQI-SEP). (2007). Evaluation of teaching quality through classroom observation: A baseline survey supplementary report (Report No. ADB-BAN-26061). Dhaka, Bangladesh: Author.

UNESCO. (2008). Supply, retention, preparation and career long professional development of teachers in E9 countries. Paris: UNESCO.

Walsh, C. S., Power, T., Khatoon, M., Biswas, S. K., Paul, A. K., Sarkar, B. C., \& Griffiths, M. (2013). The 'trainer in your pocket': Mobile phones within a teacher continuing professional development program in Bangladesh. Professional Development in Education, 39(2), 186-200.

Parsons, D., \& Ryu, H. (2006, April). A framework for assessing the quality of mobile learning. In Proceedings of the International Conference for Process Improvement, Research and Education (pp. 17-27).

Rahman, M., \&Akter, N. (2015). 'ICT-Periodism'in the Classroom: Lessons Learnt from English in Action. International Journal of Science and Research, 4(2), 1330-1334.

Rahman, M. M., \& Pandian, A. (2016). The Gap between Research and Practice in the Field of SLA: The Rationale behind It and Bridging the Gap. Journal of Applied Linguistics and Language Research, 3(3), 162-172.

Schuck, S., Aubusson, P., Kearney, M., \& Burden, K. (2013). Mobilising teacher education: A study of a professional learning community. Teacher Development, 17(1), $1-18$.

Seargeant, P., \& Erling, E. J. (2011). The discourse of 'English as a language for international development': Policy assumptions and practical challenges. Dreams and Realities.

Shaheen, R., Walsh, C., Power, T., \& Burton, S. (2013). Assessing the impact of largescale teacher professional development (TPD) in Bangladesh: English in Action (EIA).

Sharples, M., Arnedillo-Sánchez, I., Milrad, M., \& Vavoula, G. (2009). Mobile learning. In Technology-enhanced learning (pp. 233-249). Springer Netherlands.

Shohel, M., \& Banks, F. (2012). School-based teachers' professional development through technology-enhanced learning in Bangladesh. Teacher Development, 16(1), 2542 .

Shohel, M. M. C., \& Kirkwood, A. (2012). Using technology for enhancing teaching and learning in Bangladesh: challenges and consequences. Learning, Media and Technology, 37(4), 414-428.

Shohel, M. M. C., \& Power, T. (2010). Introducing mobile technology for enhancing teaching and learning in Bangladesh: teacher perspectives. Open learning, 25(3), $201-$ 215 .

Shrestha, P. (2011). The potential of mobile technologies for (English) language learning in Nepal. Journal of NELTA, 16(1-2), 107-113. 
Shrestha, P. (2012). Teacher professional development using mobile technologies in a large-scale project: Lessons learned from Bangladesh. International Journal of Computer-Assisted Language Learning and Teaching, 2(4), 34-49.

Tasnim, S. (2006). Job Satisfaction among Female Teachers: A study on primary schools in Bangladesh (Master's thesis, The University of Bergen).

UNESCO. (2008). Supply, retention, preparation and career long professional development of teachers in E9 countries. Paris: UNESCO.

Walsh, C., \& Power, T. (2011). Rethinking development and the use of mobile technologies: Lessons from Bangladesh.

Walsh, C. S., Power, T., Khatoon, M., Biswas, S. K., Paul, A. K., Sarkar, B. C., \& Griffiths, M. (2013). The 'trainer in your pocket': Mobile phones within a teacher continuing professional development program in Bangladesh. Professional Development in Education, 39(2), 186-200. 